\title{
PREVALENCE OF CARPAL TUNNEL SYNDROME AND ITS CORRELATION WITH PAIN AMONGST FEMALE HAIRDRESSERS
}

BEKIR ENES DEMIRYUREK ${ }^{1}$ and ASLI AKSOY GÜNDOĞDU ${ }^{2}$

${ }^{1}$ Sakarya University, Sakarya, Turkey

Training and Research Hospital, Department of Neurology

${ }^{2}$ Namık Kemal University, Tekirdağ, Turkey

School of Medicine, Department of Neurology

\begin{abstract}
Objectives: Carpal tunnel syndrome (CTS) may develop with repetitive and forced movements of the hands and wrists. In this study, we have aimed to evaluate whether the frequency of CTS is increased amongst female hairdressers as compared with unemployed women or not. Besides, we have also analyzed whether the functionality and pain intensity levels amongst female hairdressers with CTS are different from the ones of unemployed women with CTS or not. Material and Methods: The consecutive female hairdressers and unemployed women who had referred to our electroneuromyography (ENMG) laboratory for the upper extremity nerve conduction studies were included. They were evaluated in terms of clinical and ENMG findings, socio-demographic characteristics, functionality and pain intensity levels determined with the Boston CTS Questionnaire and visual analog scale (VAS). Results: In this study, 110 women (70 female hairdressers and 40 unemployed women) were included. The frequency of CTS among hairdressers (74.3\%) was higher than the one of the unemployed control group $(55 \%)(\mathrm{p}=0.032)$. We detected that as the time period of occupation in hairdressing increased, the risk of developing CTS also increased among hairdressers $(\mathrm{p}<0.001)$. Additionally, pain intensity and functional loss levels were higher for hairdressers with CTS than those for the control group with CTS ( $p=0.005, p<0.001$, $p=0.028$, respectively). Conclusions: The frequency of CTS is elevated for female hairdressers with respect to the unemployed women as in many other occupations requiring forced or repetitive hand movements. Besides, the occupational exposure in hairdressing also results in more elevated pain intensity and functional loss levels related with CTS as compared with the unemployed subjects. Int J Occup Med Environ Health 2018;31(3):333-339
\end{abstract}

Key words:

Pain, Carpal tunnel syndrome, Hairdressers, Female workers, Boston Questionnaire, Neuropathy

\section{INTRODUCTION}

Carpal tunnel syndrome (CTS) is an entrapment neuropathy that occurs as a result of compression of the median nerves due to the increase in the pressure in carpal tunnel [1]. Various systematic diseases (e.g., diabetes mellitus, thyroid dysfunction, and rheumatoid arthritis), pregnancy, obesity, osteoarthritis, and repetitive wrist movements could precipitate the development of CTS [1-3].

Prevalence of CTS is higher for women and in several occupational groups [1]. Depending on the nature of various professions, CTS may develop as a result of using vibratory instruments, frequent hand flexion and extension, and

Received: July 17, 2016. Accepted: July 24, 2017.

Corresponding author: B.E. Demiryurek, Sakarya University, Training and Research Hospital, Department of Neurology, Adnan Menderes Street 63, 54300 Sakarya, Turkey (e-mail: bekirenes@mynet.com). 
forceful wrist movements [4-6]. Hairdressing is associated with using some devices and techniques which are believed to precipitate the several health problems like CTS, tendinitis and epicondylitis. It is reported that prevalence of CTS for hairdressers is higher as compared to the rest of the society due to the usage of scissors and other tools for a long time [7].

To the best of our knowledge, there is limited information regarding the relation of CTS and hairdressers in our community. In this study, we have aimed to evaluate whether the development of CTS is associated with occupational factors among female hairdressers or not. Besides, we have also analyzed CTS-related pain level and functionality for female hairdressers with CTS.

\section{MATERIAL AND METHODS}

\section{Study population}

This study was conducted in the electroneuromyography (ENMG) laboratory of our neurology clinic between March 1, 2016 and April 30, 2016. The consecutive female hairdressers and unemployed women who were referred to our ENMG laboratory for the upper extremity nerve conduction studies were included. Inclusion criteria were determined as follows: being female, being aged between 18-45 years old, being voluntary to participate in the study (for both groups), being a hairdresser (for the hairdresser group) and being unemployed or not working regularly (for the control group). Male subjects were not included in the study.

The patients who had history of neurologic or psychiatric disorders such as polyneuropathy, radiculopathy or stroke, and medical histories that might cause chronic pain and precipitating CTS such as diabetes mellitus, thyroid disease, wrist fracture, connective tissue disorder, rheumatoid arthritis, morbid obesity, vitamin $\mathrm{B}_{12}$ deficiency, peripheral circulatory failure were excluded from the study. All subjects in the study and control group were age and body mass index (BMI) matched.
The aim of the study has been explained to all participants. Each participant read and signed an informed consent form. Our study was approved by the Sakarya University, Faculty of Medicine Ethics Committee.

Each participant was examined by the same neurologist. Each participant was diagnosed as having CTS or not based on typical findings in disease history and physical examination. Typical CTS findings were defined as the presence of recurring nighttime or activity-related numbness or tingling involving the palmar aspects of at least 2 of first 4 fingers and relief of the symptoms with hand shaking completely or partially. The presences of positive Tinnel or Phalen's test and of median nerve sensory or motor deficit were considered as supportive findings for the diagnosis. Therefore, the participants were divided into 2 groups as hairdressers and controls.

Demographic data (age, being a hairdresser or not, employment period) was recorded. The patients with CTS also filled in the Boston Carpal Tunnel Syndrome Questionnaire [8] and Visual Analog Scale [9] in order to evaluate pain intensity levels and functionality.

\section{Nerve conduction studies}

Nerve conduction study was conducted on both arms (total: $\mathrm{N}=220$ ) at room temperature by using Nihon Cohden electromyograph (EMG) device. It was conducted with superficial electrodes using standard nerve conduction techniques in accordance with the American Association of Electrodiagnostic Medicine (AAEM) practice guidelines [10]. Median and ulnar nerve sensory and motor conduction studies were conducted, and $\mathrm{F}$ wave responses of both nerves were recorded. Upper extremity needle ENMG studies were carried out in order to exclude cervical radiculopathy. In order to exclude polyneuropathy, sural nerve sensory conductions were examined in both lower extremities, and peroneal and tibial motor nerve conductions were examined in a lower extremity. We measured the amplitudes and latencies of 
median and ulnar motor nerve responses by supramaximal stimulation technique over abductor pollicis brevis and abductor digiti minimi muscles. Sensory conductions were evaluated from 2nd and 5th fingers, respectively. Our laboratory normative values for median nerve conduction studies were as follows: $<4.2 \mathrm{~ms}$ for distal motor latency (DML), > $6 \mathrm{mV}$ for compound muscle action potential (CMAP) amplitude, $>50 \mathrm{~m} / \mathrm{s}$ for motor conduction velocity (MCV), $<3.5 \mathrm{~ms}$ for distal sensory latency, $>15 \mu \mathrm{V}$ for sensory nerve action potential (SNAP) amplitude and $>45 \mathrm{~m} / \mathrm{s}$ for sensory conduction velocity (SCV).

Ulnar and median sensory nerve conduction studies were also applied over wrist-to-fourth finger segment for the hands in which the standard nerve conduction studies were normal. The distal sensory latency difference over than $0.4 \mathrm{~ms}$ between median and ulnar nerve were accepted as abnormal for the fourth finger sensory conduction studies [11]. The patients with CTS were graded in 4 groups based on nerve conduction study findings [12]:

- no CTS - normal median nerve conduction values,

- mild CTS - decreased median nerve SCV and normal median nerve DML,

- moderate CTS - decreased median nerve SCV and prolonged DML,

- severe CTS - absence of median SNAP and prolonged DML.

\section{Boston Carpal Tunnel Syndrome Questionnaire (BCTSQ) [8]}

The questionnaire is specific to complaints of hands with CTS. It consists of 2 scales evaluating symptom severity and functional capacity [8]. Turkish validity and reliability of the questionnaire is available (Cronbach's $\alpha 0.82$ for symptom severity scale and 0.88 for functional status scale) [13]. In each item, there are 5 different questions that could be answered quantitatively with a stratified point scale from 1 to 5 . The mean score is determined by dividing the total score into the number of questions, and therefore it varies between 1 and 5. Higher scores indicate the decreasing of functional capacity more severely. Mean score is calculated individually for symptom severity and functional capacity subscales. The symptom severity scale has 11 questions whereas the functional capacity scale has 8 questions [14].

\section{Visual Analog Scale (VAS) [9]}

The patient is asked to mark the pain and paresthesia level on a ruler indicating 0 to 10 points [9]. Turkish version of VAS test has a high validity and reliability for CTS [15].

\section{Statistical analysis}

IBM SPSS 16.0 for Windows package program was used for analyzing the data. The mean values, standard deviation, and percentage rates of the data were calculated. Whether the continuous variables were normally distributed or not was determined by using Shapiro-Wilk test. While Student's t-test was used in comparison of the data showing normal distribution, Mann-Whitney $U$ test was used for analyzing the data which did not show normal distribution. The differences between categorical variables between 2 groups were calculated using the $\mathrm{Chi}^{2}$ test. In all analyses, $\mathrm{p}$ values lower than 0.05 was defined as statistically significant.

\section{RESULTS}

In total 110 patients (70 female hairdressers and 40 unemployed females) referring to our ENMG laboratory with the suspicion of CTS were included in the study. The average age was similar between the hairdresser group $(31.1 \pm 7.3$ years $)$ and the control $(29.4 \pm 6.3$ years old) group $(t=1.236, p=0.219)$.

Any significant difference was not determined between the hairdressers with right upper extremity CTS and the controls. However, those for hairdressers with left upper extremity CTS and bilateral upper extremity were significantly higher than the ones in the control group (Table 1). The rate of CTS occurrence either in right or left arm 
Table 1. Carpal tunnel syndrome (CTS) occurrence for female hairdressers and unemployed women, Turkey, 2016

\begin{tabular}{|c|c|c|c|}
\hline \multirow{2}{*}{ CTS-affected extremity } & \multicolumn{2}{|c|}{$\begin{array}{l}\text { Respondents } \\
{[\mathrm{n}(\%)]}\end{array}$} & \multirow{2}{*}{$\mathrm{p}$} \\
\hline & $\begin{array}{l}\text { hairdressers - study group } \\
(\mathrm{N}=70)\end{array}$ & $\begin{array}{l}\text { unemployed - control group } \\
\qquad(\mathrm{N}=40)\end{array}$ & \\
\hline Right upper & $22(31.4)$ & $18(45.0)$ & 0.216 \\
\hline Left upper & $36(51.4)$ & $11(27.5)$ & 0.017 \\
\hline Bilateral upper & $32(45.7)$ & $11(27.5)$ & 0.045 \\
\hline
\end{tabular}

was higher in the hairdresser group (74.3\%) as compared with the control group $(55 \%)(\mathrm{p}=0.032)$.

Professional working years of hairdressers with CTS were significantly longer than those of hairdressers with no CTS $(15.1 \pm 6.8$ vs. $6.7 \pm 5, \mathrm{p}<0.001)$. Any significant difference was not determined between the hairdressers with CTS and the controls with CTS in terms of distribution based on electrophysiological grades of CTS (Table 2). However, the means of symptom severity subscale and functional capacity subscale scores of BCTSQ for hair-

Table 2. Carpal tunnel syndrome (CTS) severity based on nerve conduction examination for female hairdressers and unemployed women, Turkey, 2016

\begin{tabular}{lcccc}
\hline \multirow{2}{*}{$\begin{array}{c}\text { CTS occurrence } \\
\text { and its grade* }\end{array}$} & \multicolumn{2}{c}{$\begin{array}{c}\text { Respondents } \\
{[\mathrm{n}(\%)]}\end{array}$} & \multirow{2}{*}{ Chi $^{2}$} & $\mathrm{p}$ \\
\cline { 2 - 3 } & $\begin{array}{c}\text { hairdressers - study group } \\
(\mathrm{N}=70)\end{array}$ & $\begin{array}{c}\text { unemployed - control group } \\
(\mathrm{N}=40)\end{array}$ & & \\
\hline No CTS & $18(25.7)$ & $18(45.0)$ & & \\
With CTS (total) & $52(74.3)$ & $22(55.0)$ & 4.300 & 0.032 \\
mild & $21(40.4)$ & $13(59.1)$ & 2.178 & 0.140 \\
moderate & $14(26.9)$ & $4(18.2)$ & 0.642 & 0.423 \\
severe & $17(32.7)$ & $5(22.7)$ & 0.735 & 0.391 \\
\hline
\end{tabular}

* The more severe grade is labeled if the respondent has bilateral CTS.

Table 3. Carpal tunnel syndrome (CTS) severity based on questionnaires for female hairdressers and unemployed women, Turkey, 2016

\begin{tabular}{lcccrr}
\hline \multicolumn{1}{c}{ Questionnaire/Scale } & \multicolumn{2}{c}{$\begin{array}{c}\text { Score } \\
\text { [pts] }\end{array}$} & & & \\
\cline { 2 - 3 } & $\begin{array}{c}\text { hairdressers with CTS } \\
(\mathrm{N}=52)\end{array}$ & $\begin{array}{c}\text { unemployed with CTS } \\
(\mathrm{N}=22)\end{array}$ & & \\
\hline Boston Carpal Tunnel Syndrome Questionnaire [8] & & & & \\
symptom severity scale & $32.0 \pm 10.9$ & $25.0 \pm 11.2$ & -2.788 & 0.005 \\
functional capacity scale & $19.6 \pm 8.1$ & $12.6 \pm 5.3$ & -4.000 & $<0.001$ \\
Visual Analog Scale [9] & $5.6 \pm 2.2$ & $4.4 \pm 1.9$ & -2.198 & 0.028 \\
\hline
\end{tabular}

* Mann-Whitney U test. 
dressers with CTS were significantly higher than the ones in the controls with CTS. Besides, the mean score of VAS for pain for the hairdressers with CTS were significantly higher than the one in the controls with CTS (Table 3).

\section{DISCUSSION}

The occurrence rate of CTS is revealed to be higher for several occupations, particularly those requiring forced or repetitive hand movements. In this study, the frequency of CTS was determined to be higher for hairdressers than those for the control group. The pain intensity and functional loss rate was higher for hairdressers with CTS than those for controls with CTS. The long professional working years of hairdressers increased the risk of CTS and the pain intensity level related with CTS.

Carpal tunnel syndrome is a frequently seen public health problem. Although diverse tests and methods have been proposed for the diagnosis of CTS, clinical findings and electrophysiological evaluations are regarded as the most reliable diagnostic tools [16]. Robinson et al. have used the sum of the 3 comparison tests just described to improve the reliability as well as the sensitivity and specificity of NCS to diagnose CTS. Abnormal is defined as $0.9 \mathrm{~ms}$ and has a sensitivity of $83 \%$ and specificity of $95 \%$ [17]. Even though its incidence is reported to be in a large interval such as $0.1-10 \%$, CTS is observed more frequently for employed people than unemployed people in the general population [18-21].

Hairdressing is a common occupation as a service sector in Turkey, and hairdressers use their hands intensively while working. To the best of our knowledge, there was not any isolated study indicating the frequency of CTS among hairdressers in the current literature or the one analyzing whether the hairdressing profession was a risk factor development of CTS or not. In a study of Bradshaw et al., it was reported that hairdressers had more musculoskeletal disorders and higher associated pain intensity levels than controls analyzing occupational exposure related dis- orders [22]. In another study, Armstrong et al. reported that CTS, epicondylitis and tendinitis were frequently observed among hairdressers [7].

In this study, we have detected that the CTS frequency among hairdressers is higher than for the control group composed of unemployed participants. As there was a great difference in the rate of CTS in left sides of hairdressers as compared with the ones of unemployed subjects, we have suggested that the constant flexion-extension movement in wrist to use the scissors, hair dryers and blow dryers strain the left arms of the hairdressers more than right side. Besides, the forced steadiness of the left wrist in flexion position during the usage of combs while cutting and flattening the hairs could probably cause the thickening of flexor retinaculum gradually and therefore development of CTS prominently in left arms of hairdressers within years. Future studies with larger study populations are needed to report hairdressing profession as an absolute risk factor for CTS. Carpal tunnel syndrome and other musculoskeletal system disorders developing due to many occupations cause labor losses and pain symptoms. As indicated in the studies, pain and functional capacity losses in upper extremities developing due to CTS cause disability and decrease patients' life quality [22-24]. In a study evaluating risk of disease due to the hairdressing profession, the pain level occurring due to CTS and other musculoskeletal system disorders was reported to be higher for hairdressers as compared to those who were not hairdressers. The researchers suggested that the reason of the pain was associated with staying standing up for a long time, working in leaning posture and long-lasting repetitive movements [22].

We have found that hairdressers with CTS have significantly higher mean occupational periods than those without CTS. We have also suggested that this is correlated with duration of occupational exposure and severity of electrophysiological findings, in accordance with the previous research. Furthermore, the scores of BCTSQ which is used for evaluation of pain level and functional capac- 
ity in CTS and ones of VAS which is used for assessment of pain intensity level are found to be high and correlated with severity of electrophysiological findings in many studies [25-27].

In accordance with that, the BCTSQ and VAS scores are significantly higher for hairdressers with CTS than for unemployed subjects with CTS in our study. We have thought that the reason is that CTS determined with electrophysiological methods are more common among hairdressers. We consider the lack of male hairdressers as the main limitation of this study which is conducted with the aim of determining the effect of hairdressing profession on the risk of development of CTS.

\section{CONCLUSIONS}

The frequency of CTS is elevated among female hairdressers with respect to the unemployed women as in many other occupations requiring forced or repetitive hand movements. Besides, the occupational exposure in hairdressing also results in more elevated pain intensity and functional loss levels related with CTS as compared with the unemployed subjects. Future studies are warranted to highlight whether the informing hairdressers about CTS symptoms, shortening daily working hours, receiving trainings preventing development of CTS may play an effective role in protecting from disease or not.

\section{REFERENCES}

1. Yazici J. Diseases of spinal nerves Neurology. In: Oge E, editor. Istanbul Faculty of Medicine Basic and Clinical Science text books. Istanbul: Nobel; 2004. p. 573-90.

2. Kouyoumdjian JA, Zanetta DM, Morita MP. Evaluation of age, body mass index, and wrist index as risk factors for carpal tunnel syndrome severity. Muscle Nerve. 2002;25(1):93-7, https://doi.org/10.1002/mus.10007.

3. Bland JD. Do nerve conduction studies predict the outcome of carpal tunnel decompression? Muscle Nerve. 2001;24(7): 935-40, https://doi.org/10.1002/mus.1091.
4. Ohnari K, Uozumi T, Tsuji S. Occupation and carpal tunnel syndrome. Brain Nerve. 2007;59(11):1247-52.

5. Palmer KT, Harris EC, Coggon D. Carpal tunnel syndrome and its relation to occupation: A systematic literature review. Occup Med (Lond). 2007;57(1):57-66, https://doi.org/ 10.1093/occmed/kql125.

6. Van Rijn RM, Huisstede BM, Koes BW, Burdorf A. Associations between work-related factors and the carpal tunnel syndrome - A systematic review. Scand J Work Environ Health. 2009;35(1):19-36, https://doi.org/10.5271/sjweh.1306.

7. Armstrong T, Dale AM, Franzblau A, Evanoff BA. Risk factors for carpal tunnel syndrome and median neuropathy in a working population. J Occup Environ Med. 2008;50(12):1355-64, https://doi.org/10.1097/JOM.0b013e318 $1845 \mathrm{fb} 1$.

8. Levine DW, Simmons BP, Koris MJ, Daltroy LH, Hohl GG, Fossel AH, et al. A self-administered questionnaire for the assessment of severity of symptoms and functional status in carpal tunnel syndrome. J Bone Joint Surg Am. 1993; 75(11):1585-92, https://doi.org/10.2106/00004623-19931100 0-00002.

9. Wewers ME, Lowe NK. A critical review of visual analogue scales in the measurement of clinical phenomena. Res Nurs Health. 1990;13(4):227-36, https://doi.org/10.1002/nur. 4770130405.

10. American Association of Electrodiagnostic Medicine, American Academy of Neurology, American Academy of Physical Medicine and Rehabilitation. Practice parameter for electrodiagnostic studies in carpal tunnel syndrome: Summary statement. Neurology. 1993;43(11):2404-5, https:// doi.org/10.1212/WNL.43.11.2404.

11. Havton LA, Hotson JR, Kellerth JO. Correlation of median forearm conduction velocity with carpal tunnel syndrome severity. Clin Neurophysiol. 2007;118(4):781-5, https://doi. org/10.1016/j.clinph.2006.12.011.

12. Sahin N, Albayrak I, Ugurlu H. Association between intensity of carpal tunnel syndrome and body mass index values in obese patients. Tubav Sci. 2009;2(4):484-8. 
13. Sezgin M, Incel NA, Serhan S, Camdeviren H, As I, Erdoğan C. Assessment of symptom severity and functional status in patients with carpal tunnel syndrome: Reliability and functionality of the Turkish version of the Boston questionnaire. Disabil Rehabil. 2006;28(20):1281-5, https://doi. org/10.1080/09638280600621469.

14. Heybeli N, Ozerdemoglu RA, Aksoy OG, Mumcu EF. Carpal Tunnel Syndrome: Functional and symptomatic scoring for surgical treatment survey. Acta Orthop Traumatol Turc. 2001;35:147-51.

15. Eraslan L, Yüce D, Kermalli AM, Baltaci G. [Comparison of short-term effects of rigid tape and night splint on pain and function in patient with carpal tunnel syndrome: A randomized clinical trial]. Turk J Physiother Rehabil. 2014;25(1): 8-15, https://doi.org/10.7603/s40680-014-0002-0. Turkish.

16. Kohara N. Clinical and electrophysiological findings in carpal tunnel syndrome. Brain Nerve. 2007;59(11):1229-38.

17. Robinson LR, Micklesen PJ, Wang L. Strategies for analyzing nerve conduction data: Superiority of a summary index over single tests. Muscle Nerve. 1998;21(9):1166-71, https:// doi.org/10.1002/(SICI)1097-4598(199809)21:9<1166::AIDMUS7>3.0.CO;2-5.

18. Yagev Y, Gringolds M, Karakis I, Carel RS. Carpal tunnel syndrome: Under-recognition of occupational risk factors by clinicians. Ind Health. 2007;45(6):820-2, https://doi. org/10.2486/indhealth.45.820.

19. Roquelaure Y, Ha C, Nicolas G, Pélier-Cady MC, Mariot $\mathrm{C}$, Descatha $\mathrm{A}$, et al. Attributable risk of carpal tunnel syndrome according to industry and occupation in a general population. Arthritis Care Res. 2008;59(9):1341-8, https:// doi.org/10.1002/art.24002.

20. Maghsoudipour M, Moghimi S, Dehghaan F, Rahimpanah A. Association of occupational and non-occupational risk factors with the prevalence of work related carpal tunnel syndrome. J Occup Rehabil. 2008;18:152-6, https://doi. org/10.1007/s10926-008-9125-4.

21. Chiang CL, Liao CY, Kuo HW. Postures of upper extremity correlated with carpal tunnel syndrome (CTS). Int J Occup Med Environ Health. 2017;30(2):281-90, https://doi. org/10.13075/ijomeh.1896.00566.

22. Bradshaw L, Harris-Roberts J, Bowen J, Rahman S, Fishwick D. Self-reported work-related symptoms in hairdressers. Occup Med (Lond). 2011;61(5):328-34, https://doi.org/ 10.1093/occmed/kqr089.

23. Rampel DM, Evanoff BA, Cherniac M, Evanoff BA. Musculoskeletal disorders. In: Rosenstock L, Cullen MR, Brodkin CA, Redlich CA, editors. Textbook of clinical occupational and environmental medicine. 2nd ed. China: Elsevier; 2005. p. 495-532.

24. Akbal A, Eroglu P, Yilmaz H, Tutkun E. Occupational exposures and musculoskeletal system findings. J Pharm Sci. 2012;15(3):73-6.

25. Greenslade JR, Mehta RL, Belward P, Warwick DJ. Dash and Boston questionnaire assessment of carpal tunnel syndrome outcome: What is the responsiveness of an outcome questionnaire? J Hand Surg Br. 2004;29(2):159-64, https:// doi.org/10.1016/j.jhsb.2003.10.010.

26. Ilhan D, Toker S, Kilincioglu V, Erim G. Assessment of the Boston Questionnaire in diagnosis of idiopathic carpal tunnel syndrome: Comparing scores with clinical and neurophysiological findings. Duzce Med J. 2008;3:4-9.

27. Ahamed SS, Anas MB, Aref AA, Abdulrahman AA. Prevalence and associated factors of Carpal Tunnel Syndrome (CTS) among medical laboratory staff at King Saud University Hospitals, KSA. Pak J Med Sci. 2015;31(2):331-5, https://doi.org/10.12669/pjms.312.6831.

This work is available in Open Access model and licensed under a Creative Commons Attribution-NonCommercial 3.0 Poland License - http://creativecommons.org/ licenses/by-nc/3.0/pl/deed.en. 